\title{
Options for an environmental risk assessment of intentional and unintentional chemical mixtures under REACH: the status and ways forward
}

\author{
Enken Hassold ${ }^{*}$ (I), Wiebke Galert and Jona Schulze
}

\begin{abstract}
It is acknowledged that a variety of chemicals enter the environment and may cause joint effects. Chemicals regulated under the European Chemicals Regulation REACH are often part of formulated mixtures and during their processing and use in various products they can be jointly released via sewage treatment plants or diffuse sources, and may combine in the environment. One can differentiate between intentional mixtures, and unintentional mixtures. In contrast to other substance-oriented legislations, REACH contains no explicit requirements for an assessment of combined effects, exposures and risks of several components. Still, it requires ensuring the safe use of substances on their own, in mixtures, and in articles. The available options to address intentional as well as unintentional mixtures are presented and discussed with respect to their feasibility under REACH, considering the responsibilities, communication tasks and information availability of the different actors (registrants, downstream-user and authorities). Specific mixture assessments via component-based approaches require a comprehensive knowledge on substances properties, uses, fate and behaviour, and the composition of the mixture under consideration. This information is often not available to the responsible actor. In principle, intentional mixtures of known composition can be assessed by the downstream-user. But approaches have to be improved to ensure a transparent communication and sound mixture assessment. In contrast, unintentional mixtures appear to be better addressable via generic approaches such as a mixture allocation factor during the chemical safety assessment, although questions on the magnitude, implementation and legal mandates remain. Authorities can conduct specific mixture risk assessments in well-defined and prioritized cases, followed by subsequent regulatory measures. In order to address intentional and unintentional mixtures within the current REACH framework, legal mandates together with guidance for the different actors are needed. Furthermore, further data on mixture compositions, uses and co-exposures need to be made accessible via shared databases.
\end{abstract}

Keywords: REACH, Mixtures, Environmental risk assessment, Mixture allocation factor, Co-exposure

\section{Introduction: relevance of mixtures and their assessment}

Currently, around 23000 single substances with about 100000 dossiers are registered under the European

\footnotetext{
*Correspondence: enken.hassold@uba.de

Section IV 2.3 Chemicals, German Environment Agency

(Umweltbundesamt-UBA), Wörlitzer Platz 1, 06844 Dessau-Roßlau, Germany
}

Chemicals Regulation REACH (1907/2006/EC) on "Registration, Evaluation, Authorisation and Restriction of Chemicals" [15]. A large proportion of these substances end up in a variety of mixtures, intentionally manufactured as such or containing by-products of other processes. Such intentional mixtures that contain a number of different components include wet formulations like varnishes, inks, paints (more than 20 ingredients), lacquers (10-50 ingredients), mortar 


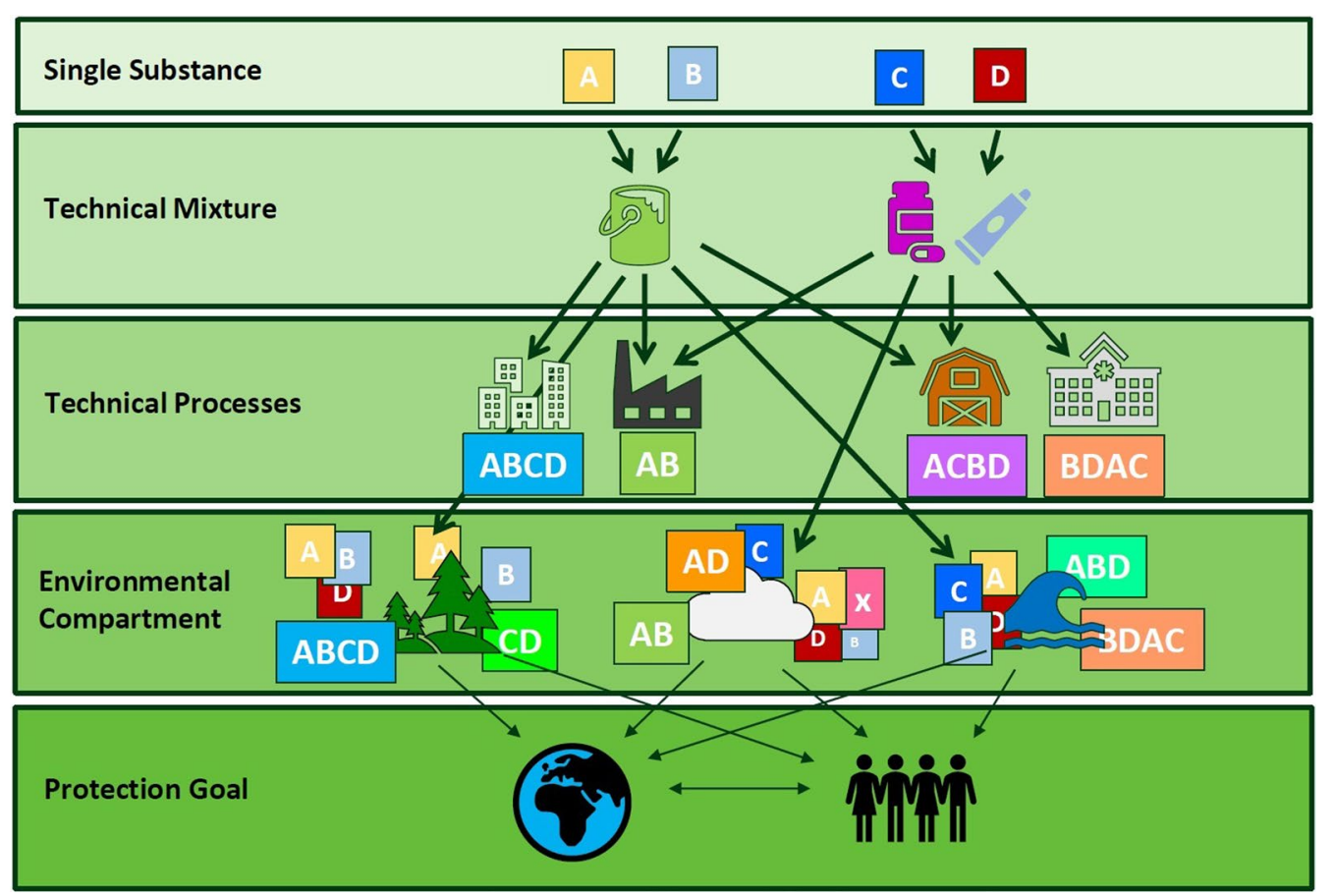

Fig. 1 Simplified overview on different levels of complexity to be considered for an environmental assessment for intentionally formulated as well as unintentional mixtures of chemicals reaching environmental compartments (surface/marine water, soil, air) via point sources (e.g. sewage treatment plants) or diffuse sources (e.g. urban run-off, depositions, or indirect exposures via man)

(1-5 ingredients), or cleaning agents (5-10 ingredients) and dry formulations like pre-formulated granules [40]. During their processing and downstream use substances are blended together in formulations, are subsequently reformulated for different uses and end up in a variety of products. During their life cycle (from production, application and service life to waste) chemicals may be introduced into the environment in various ways. They are emitted from point sources such as production plants, enter compartments from different sources, such as industrial wastewater or municipal sewage treatment plant effluents, via diffuse pathways like urban run-off from streets or buildings, as well as via waste. One can hence differentiate between formulated intentional mixtures, and unintentional mixtures in the environment (Fig. 1).

Scientific evidence on environmental exposures to multiple hazardous chemicals is increasing [44]. Data from monitoring studies of European surface waters demonstrate the co-occurrence of multiple chemicals in time and space $[11,45]$. Substance concentrations in European surface waters may exceed regulatory thresholds for single substances and potential risks have been shown to increase with the number of chemicals found $[12,46]$.

The scientific basis for an assessment of chemical mixtures is well established. It has been shown experimentally that chemicals may act jointly and that the combined toxicity may be higher than the toxicity of each of the single components on its own as reviewed by Kortenkamp et al. [43]. This may also be the case if substances are present at or below their regulatory thresholds, such as the EQS or NOEC [12, 57]. In most cases chemicals have been shown to act additively following the established concepts of Concentration Addition (CA) or Independent Action (IA). Synergisms or antagonisms, exceeding or reducing the additive ecotoxicities due to specific interactions between the chemicals are comparatively rare and restricted to specific cases [13, 47]. While CA was primary used to predict (eco)toxicities of substances with similar modes of action and IA for dissimilar modes of action, CA has been recognized as pragmatic standard in the environmental context.

Methodologies for assessing the combination effects of chemicals have been developed and experiences were gained in the academic as well as the regulatory context for mixtures of known composition. In particular, the State of the Art report by the Commission [43], the framework of the WHO International Programme on Chemical Safety (IPCS) [49] and several reviews of the Joint Research Centre and a report on behalf of the Swedish Government $[4,5,40,41,56]$ provided analyses on the state of play. Recently, basic procedures have found 
their way into overarching guidance of the Organisation for Economic Co-operation and Development (OECD) [51] and the European Food Safety Authority EFSA [50].

The issue of a risk assessment of chemical mixtures has been intensively discussed across the EU and OECD member states. Roughly 10 years ago, the Conclusions of the Environment Council [24], the Communication of the European Commission [18] together with the Opinions of the Scientific Committees SCHER/SCENHIR/ SCCS [19], already expressed the need to address combined effects. In 2012, the European Commission proposed to develop technical guidelines and science-based approaches for the assessment of chemical mixtures, and to review the progress made. Most recently, the Conclusions of the Environment Council [25] on Chemicals together with the Chemicals Strategy for Sustainability in the context of the European Green Deal [20] again highlight the need for a consideration of multiple exposures and combined effects of chemicals. The accompanying comprehensive Staff Working Document of the European Commission [22] reports the progress made on the topic and future needs.

Although current risk assessments of chemicals most often focus on individual chemicals, environmental hazards and risks arising from combination effects and exposures are already addressed in several European substance-oriented regulations with respect to intentional mixtures. These are the legislations for plant protection products (Regulation (EC) No $1107 / 2009$, PPPR), biocidal products (Regulation (EC) No 528/2012, BPR) as well as veterinary pharmaceuticals (Directive 2001/82/EC), which all require a product authorization by the authorities. These contain explicit legal requirements for the consideration of combined effects. Methods are specified in detailed guidance documents for plant protection products, e.g. [34], biocidal products [31], and veterinary pharmaceuticals [36]. These requirements are restricted to formulations, and do not consider re-formulations, sequential applications or simultaneous entries of several components. In the context of the media-oriented water framework directive (WFD) (2000/60/EC) [59], the method to derive Environmental Quality Standards (EQS) for mixtures is laid down in the common implementation plan Commission [17], without explicit obligations.

In view of the achievements of other substance-oriented legislations with respect to intentional mixtures, REACH seems to lag behind as there are no explicit legal obligations-except those referring to the CLP regulation (No 1272/2008/EC) - to assess and regulate the combined effects and exposures.

A number of authors have proposed ways forward for the regulatory assessment of combined exposures [6,
40, 44, 51, 55, 56]. Explicitly related to REACH, only few proposals for a mixture risk assessment are available [2, 8]. For the environment, Bunke et al. [10] provided an in-depth analysis of options for different actors under REACH to address intentional as well as unintentional mixtures. Recently, Rudén et al. [56] came up with more specific proposals for REACH to improve the consideration of combination effects and grouping of chemicals.

\section{Aims and methodology}

This regulatory review compiles the necessary background information on the functioning of REACH and central methods for a mixture assessment that is needed for a critical analysis of the available options and challenges to address intentional and unintentional mixtures within REACH. The present paper has a clear focus on the environment. The aim is to provide a comprehensive basis for the on-going discussions at EU level around the possible options and the European Commissions proposal for an introduction of a so-called "mixture assessment factor" within REACH. Although the topic is relevant for other legislations and their interplay, the work focuses on REACH and assessments and regulatory measures for mixtures in the environment. For the analysis of possible policy options, the current legal obligations, different responsibilities, communication tasks, and information availability for the different actors (registrants, downstream-user and authorities) are considered.

For this purpose, recent reports on the issue were evaluated and referred to after a non-systematic and nonexhaustive literature research. This included the legal text of the REACH regulation, its accompanying guidance documents as well as experiences from regulatory practise. An early starting point was a development and research project on behalf of the German Environment Agency [10] complemented by own analyses.

\section{Background: how does REACH work? Data availability, tasks and communication of the different actors}

$\mathrm{REACH}$ is a typical single substance-oriented regulation and hence addresses single substances. In contrast to other substance regulations, REACH includes neither an authorization of single substances per se nor a product authorization of intentional mixtures. It also shifts the burden of proof: not authorities, but manufacturer and importer of chemicals (registrants) together with the downstream users (e.g. formulator) are responsible for the data generation, safety assessment and derivation of safe use conditions for single chemicals.

Although REACH aims at creating a comprehensive data basis for its 22873 registered chemicals (ECHA dissemination website $07 / 2020$ [62]), data availability and 


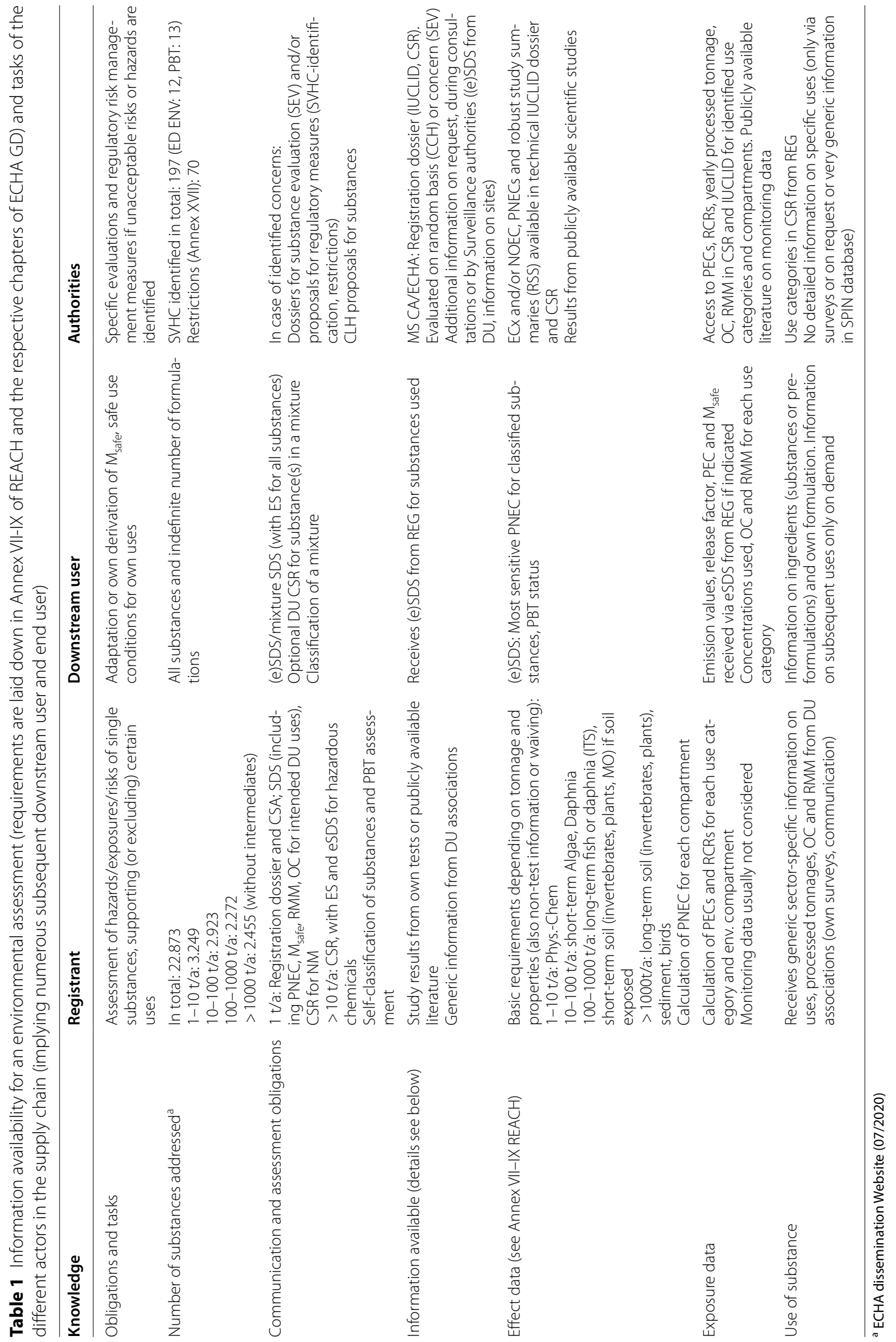


quality varies greatly for substances. Data availability is depending on production volumes and substance properties according to the data requirements defined in Annex VII-X. In particular for substances marketed at low tonnages $<10$ t/a, ecotoxicity data are very limited. Exposure scenarios are only available for certain hazardous substances and at higher tonnages. Environmental data availability is often restricted to certain actors (Table 1).

\section{The registrants: chemicals safety assessment}

Substances with volumes $>1 \mathrm{t} / \mathrm{a}$ have to be registered by the manufacturer and importer of single chemicals. For substance in volumes greater than $10 \mathrm{t} / \mathrm{a}$ registrants have to conduct a chemical safety assessment (CSA). An exposure and risk assessment need to be conducted for classified substances, substances assessed as persistent, bioaccumulative and toxic (PBT), or substances with hazardous effects (Article 14.4). Information on intrinsic properties, fate and behaviour, as well as hazards and risks are documented in a chemical safety report (CSR) as part of the registration dossier (REACH article 14.1).

For the risk assessment, risk characterization ratios $(\mathrm{RCR}=$ Predicted Environmental Concentration (PEC)/ Predicted No Effect Concentration (PNEC)) are derived for each compartment (air, aquatic water and sediment, marine water and sediment, terrestrial environment) and for each intended use (described in a standardized way by means of the use descriptor system). An $R C R<1$ indicates that the identified risks are acceptable. The PNEC is derived using effect concentration(s) from ecotoxicity tests with representative species (e.g. algae, daphnids, and/or fish) together with defined assessment factors taking into account the data availability and uncertainties related to the complexity of ecosystems as laid down in guidance R.7b of the European Chemicals Agency (ECHA). PECs are calculated on the basis of generic emission factors according to ECHA Guidance on environmental exposure assessment R.16 [29]. The PEC estimate represents local concentrations, considering daily release rates, dilution in the sewage treatment plant and receiving waters as well as regional background concentrations. The background concentrations are based on averaged, aggregated, annual concentrations of a substance across all life cycle steps for a standard region. The PEC and emission factors may be refined using so-called specific environmental release categories (spERCs), developed by industry associations, or monitoring data.

In order to estimate the maximum amounts of a substance that may be used during production, and hence "safely" emitted to environmental compartments, the so-called maximum safe use amount or " $\mathrm{M}_{\text {safe }}$ " $(\mathrm{kg} / \mathrm{day}$ or $\mathrm{kg} /$ year) is calculated using the PEC and the emission days. In case unacceptable risks $(\mathrm{RCR}>1)$ are identified, additional operational conditions (OCs) or risk mitigation measures (RMM), such as adapted filter systems or wastewater cleaning steps, are applied to achieve a safe use.

The registrant is obliged to communicate only the basic information for a substance via safety data sheets (SDS) or, in case of a required risk assessment, additionally the exposure scenarios in the so-called extended safety data sheets (eSDS) to the downstream user (REACH articles 14.4 and 31.7). In case of an eSDS, the basic substance information shall include the (most sensitive) PNECs, estimated safe use amounts $\left(\mathrm{M}_{\text {safe }}\right)$, safe use conditions, exposure scenarios and risk reduction measures.

The downstream users: check and adaptations for own use Being responsible for the safe use of the substances, mixtures and articles they process, downstream users (DUs) are obliged to check via the (e)SDS whether the classification of substances and intentional mixtures is correct, whether their application is covered, and whether the described conditions ensure that risks are controlled (i.e. $\mathrm{RCR}<1$ ) for their intended use. In case of deviations, the DU has to conduct an own safety assessment, adapt the safe use conditions and/or amounts. If a use is not covered by the registrants' exposure scenario, the DU has to notify ECHA, ask the registrant to integrate his use into the registration dossier, or provide an own DU CSR (REACH articles 37.4 and 31.2).

The DU is further obliged to communicate the result of his DU assessment, the information on single components, the classification and labelling of his formulated mixture, a corresponding exposure scenario, and summary of risk mitigation measures via the eSDS to subsequent DUs and end user (REACH Annex II and title IV, Article 31 and 38). The DU also informs the registrant on his uses via the so-called upstream communication in a very generalized form as use categories, respecting the confidentiality of recipes for formulations.

\section{The regulatory measures of authorities}

The regulatory authorities (ECHA, member state authorities) evaluate the standard data provided by the registrants in the technical dossiers and the chemical safety reports on a random basis during compliance checks of dossiers $(\mathrm{CCH})$ and during testing proposal evaluations (TPE). Member state authorities may evaluate substances in more detail using all available information during the formal substance evaluation (SEV), if concerns and potential hazards/risks for the environment are indicated and justified. These substances are published on ECHA's Community Rolling Action Plan (CoRAP) list [61]. Following these evaluations further test data or information 


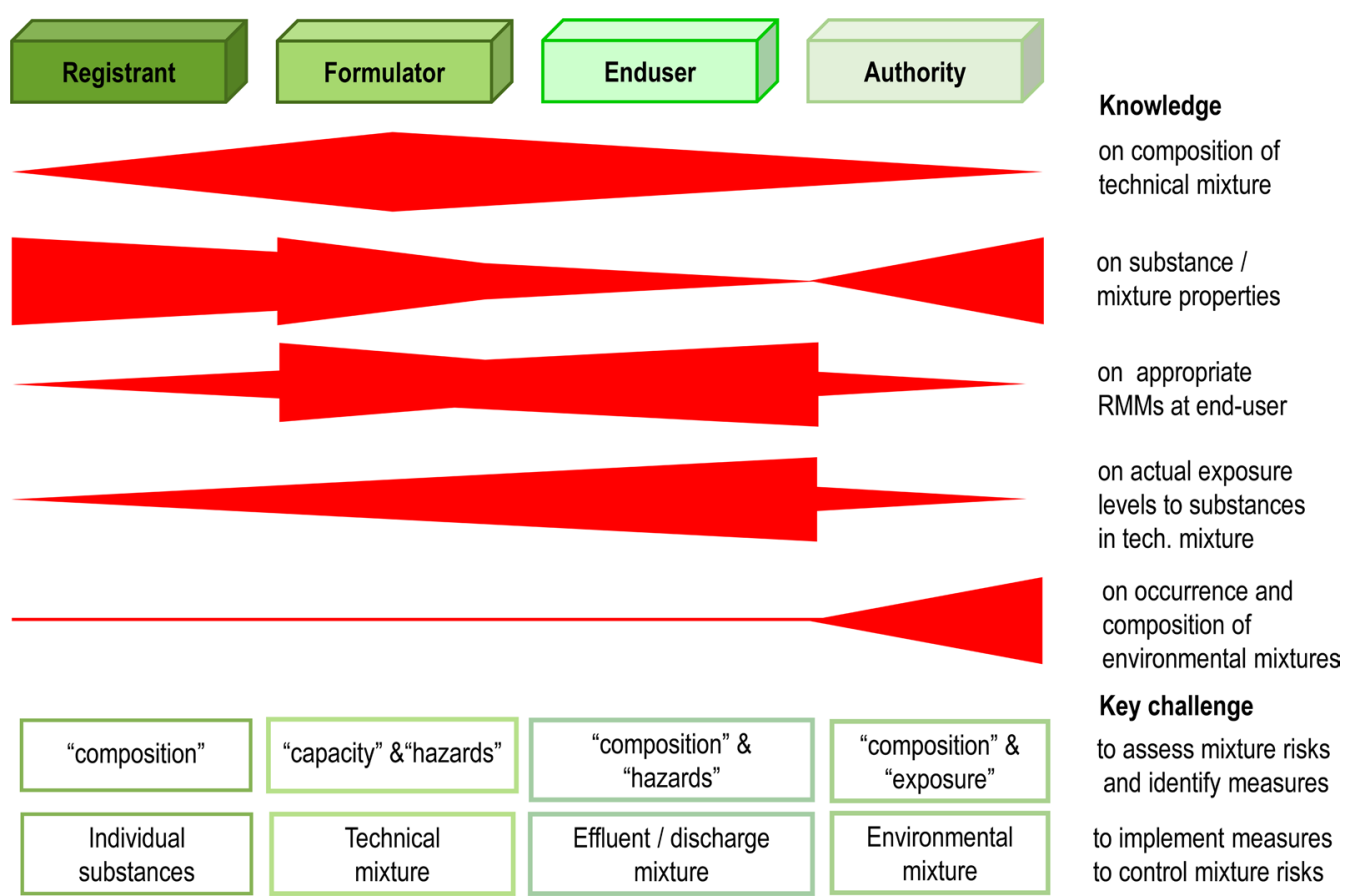

Fig. 2 A challenge for communication — distribution of knowledge relevant for mixture assessment between the different actors and along the supply chain (adapted after [10])

Table 2 Definitions and terms: different types of a mixture (according to, i.e. [10] and current definitions under REACH

\begin{tabular}{|c|c|}
\hline Term & Explanation \\
\hline "Substance" & $\begin{array}{l}\text { Defined in REACH. Mono-component or multi-component substance (MCS), substance of unknown or } \\
\text { variable composition or biological materials (UVCB) }\end{array}$ \\
\hline "Article" & Defined in REACH. Composition of different components on the basis of a specific function \\
\hline "Mixture" & $\begin{array}{l}\text { Defined in REACH. Intentionally formulated mixture marketed as such. On a general level the term mix- } \\
\text { ture may refer to both intentional and unintentional mixtures }\end{array}$ \\
\hline Aggregated exposure/effects & $\begin{array}{l}\text { Effects or exposures of single substance via multiple pathways/life cycle steps entering the same environ- } \\
\text { mental compartment }\end{array}$ \\
\hline Combined or cumulative exposure/effects & $\begin{array}{l}\text { General level referring to effects or exposures of multiple substances via the same or multiple pathways/ } \\
\text { life cycle steps entering the same environmental compartment. In REACH, "combined risks" in the CSR } \\
\text { currently refers to single substances in the sense of aggregated exposures, which is not meant here }\end{array}$ \\
\hline Intentional mixture & General level, referring to intentionally formulated mixture marketed as such ("mixture" under REACH) \\
\hline Unintentional mixture & $\begin{array}{l}\text { General level, referring to all unintentional released mixtures and comprises co-incidental, discharge and/ } \\
\text { or environmental mixtures }\end{array}$ \\
\hline Discharge mixture & $\begin{array}{l}\text { Mixture of substances from a production plant or sewage treatment plant, unintentional jointly released } \\
\text { to surface waters. This term is not mentioned under REACH (e.g. [10]) }\end{array}$ \\
\hline Coincidental and/or environmental mixture & $\begin{array}{l}\text { Complex mixtures, entering environmental compartments from different sources and pathways uninten- } \\
\text { tionally. It must be clear whether substances regulated under one or various legislations are considered. } \\
\text { These terms are not mentioned under REACH (e.g. [10]) }\end{array}$ \\
\hline
\end{tabular}

on exposures or certain hazardous properties (e.g. endocrine disruption) may be requested from registrants.

If certain hazards or a risk is concluded, further regulatory measures may be proposed by member state authorities. The identification as substance of very high concern (SVHC) leads to an inclusion in the candidate list [63] and certain information obligations to DU and consumers, a possible prioritization for inclusion in Annex XIV [67] and the authorization procedure. A second regulatory measure is the restriction of certain uses by inclusion of substances in the Annex XVII of REACH [64]. 
The challenge: communication of information between the actors

Within $\mathrm{REACH}$, there is a discrepancy with respect to the degree of knowledge, and the different responsibilities between the registrants and DU (Fig. 2). The registrant has detailed information on the substance properties, but is not obliged to cover every single use condition for his substance during its lifecycle and only receives very generic information on the intended uses from the DUs (due to confidentiality reasons) via upstream communication. The DUs have more detailed information on their own specific uses such as the composition of a specific mixture they prepare and the obligation to forward basic information on the intentional mixtures they sell, formulate or process in the supply chain according to REACH titles IV and V via safety data sheets during downstream communication. However, they only receive limited information on their ingredients via the (e)SDS from the registrants and eventually previous suppliers. The regulatory authorities only get insight into chemical safety assessment reports of registrants, but usually will not receive information from DU.

\section{Legal obligations enabling an environmental risk assessment of mixtures under REACH Definitions for substances and mixtures}

As stated above, REACH focuses on single substances. Besides substances as such, REACH refers to single substances in mixtures and in articles, where several substances are intentionally blended. So-called multi-constituent substances (MCS) and substances of unknown or variable composition and biological materials (UVCB) are defined as single substances under the $\mathrm{REACH}$ regulation. $\mathrm{REACH}$ defines a mixture as a combination of two or more substances, blended intentionally in a formulation. In light of around 23000 registered single chemicals, the number of formulated intentional mixtures under $\mathrm{REACH}$ is high-concrete numbers remain unknown. Emissions of one single substance from different sources is often referred to as combined exposure under REACH. We use the term aggregated exposure. REACH does not refer to unintentional mixtures.

However, during their production and life cycle, substances may be emitted from a production plant, a sewage treatment plant (point sources) or via a variety of pathways, and subsequently enter environmental compartments (diffuse sources). Hence, it is important to differentiate between intentional and unintentional mixtures and address different levels of complexity (Fig. 1).

In order to reach a common understanding terms such as technical mixtures, discharge mixtures, co-incidental mixtures, or environmental mixtures have been introduced by several authors [10, 41, 51], which are summarized in the Table 2.

\section{Obligations under REACH enabling mixture assessments}

Within $\mathrm{REACH}$ there are no clear legal obligations to address possible risks arising from joint effects and exposures of the components in a formulated mixture or later co-exposures in the environment. However, $\mathrm{REACH}$ explicitly addresses the safe use of single substances on their own, in (intentional) mixtures and in articles throughout their life cycle and obliges registrants and DU to assess and ensure safe use conditions (REACH Art. 17, Art. 10).

As laid down in the respective guidance documents $[27,28]$, DU have the obligation to check that their use of substances in mixtures is covered by the corresponding exposure scenario(s), but the simultaneous use of several hazardous substances is not explicitly addressed. For the registrant, there is no obligation for a mixture assessment-mixtures are not registered or listed. But potential emissions of a single substance via different sources and its uses during its life cycle and along the supply chain-so-called aggregated exposures-are taken in account for the calculation of the PEC by the registrants (see Annex I 6.2 and ECHA Guidance Documents R.12, R.16 and R.18) [9].

\section{Classification and labelling of substances and mixtures}

The regulation for classification, labelling and packaging (CLP) (Regulation (EC) No 1272/2008) [16] and its guidance on the application of the CLP criteria [30] are key instruments for $\mathrm{REACH}$ providing the basis for communication of hazard data on substances and intentional mixtures along the supply chain. Intentional mixtures have to be classified and labelled by companies considering additive effects of hazardous components by either testing the whole mixture as such or, by applying the additivity or summation method to determine the ecotoxicity. Self-classifications are conducted by each company on their own for substances and mixtures without further approval by authorities. These classifications may differ for the same substance between different companies that are coming to diverging conclusions and subsequently also vary for identical formulated mixtures. Lists on classified mixtures are not available. For single substances, authorities can propose harmonized classifications, which are included in Annex VI to the CLP Regulation. Both the self-notified as well as harmonized classified substances are listed in ECHAs inventories [65, 66]. 


\section{Further obligations under REACH enabling future mixture} assessments

In order to close data gaps and limit tests to only a few representatives, the assessment of multi-component substances (such as MCS or UVCB) makes use of the "summation method" based on the concept of CA to estimate overall ecotoxicities. This is described in REACH Annex I, section 0.4 and Annex XI section 1.5, as well as ECHA guidance R6 on grouping of chemicals [26] and the read across assessment framework (RAAF) [32]. For substances originating from petroleum or coal streams, the so-called PetCo substances, the Hydrocarbon block methodology (HCBM) [42] is used to assess the risks of complex substances based on the known properties of their similar constituents or blocks.

In the context of the authorities' evaluations of substances that may give rise to concern, group-wise assessments of structural related substances are explicitly referred to in the legal text (REACH Title VI articles 44.1a, and 47). Also, REACH Annex XVII on restrictions contains entries for groups of related substances. In the context of granting authorizations for substances listed in Annex XIV, 'all discharges, emissions and losses including risks arising from diffuse or dispersive use' shall be taken in account (REACH Title VII, article 60.2).

\section{Approaches for a specific mixture assessment General principles}

General procedures for specific mixture risk assessments are in principle the same for intended and unintentional mixtures and have been reviewed for example by [43, 50, 51]. Approaches for the environmental assessment of intentional mixtures have already been implemented in guidance documents in the context of the product authorization of plant protection products [37], biocidal products [31], and veterinary pharmaceuticals [36].

Procedures include the definition of the composition of the mixture under consideration, testing of whole mixtures when available or component-based approaches using the concepts CA or IA on the basis of ecotoxicity data (i.e. effect concentrations or reference values) to calculate mixture toxicities. Together with exposure concentrations of the components (i.e. predicted or measured), a summation of the risk characterization ratios (RCRmix $<1$ ), of the components often is used to characterize the risks. On this basis, the identification of possible drivers of ecotoxicity and/or risks is possible.

\section{Composition of a mixture}

While the composition and concentrations of ingredients of an intentional mixture are in the best case known to the formulator, the composition of unintentional mixtures is often difficult to define. Defining unintentional releases or mixtures in an environmental compartment rely on the availability of data on co-occurrences which often varies spatially and temporally. While effluents might be defined and assessed by production plant operators, an assessment of complex mixtures requires monitoring data on co-occurrences in environmental compartments and a prioritization of substance and mixtures of concern.

\section{Criteria to include components}

Both for intentional as well as unintentional mixtures, criteria are needed to define which components to consider for the mixture assessment as not all ingredients may be relevant. Besides substances that are classified as hazardous to the environment according to CLP/ GHS, in particular substances of concern under REACH, such as identified SVHC (PBT, vPvB, PMT, vPvM, ED ${ }^{1}$ ) are important to be considered. The same would apply to priority (hazardous) substances $(\mathrm{P}(\mathrm{H}) \mathrm{S})$ of the water framework directive and further substances classified as hazardous on a national level (e.g. German regulation on substances hazardous to water AWSV/22/2017 [71]).

Criteria can also be based on certain concentrations or percentages in a formulation. Here, it is to consider that possible additive effects may also occur in low individual concentrations of the components and that also substances with dissimilar modes of action may produce additive effects [43].

The "maximum cumulative ratio" (MCR) approach can be used as tool to decide on the need for a refined assessment of (intentional or unintentional) mixtures [52, 53]. It is based on the ratio between the toxicity of a mixture as predicted by $\mathrm{CA}$ and the toxicity of the most contributing chemical in the mixture. The calculation of the MCR involves a rough mixture risk assessment by summing up the risk quotients of all the components. Here, two basic scenarios would trigger a mixture assessment: either one to few constituents are driving the mixture toxicity (so-called "drivers") or several substances contribute rather equally at lower individual concentrations to the overall toxicity [53]. Both scenarios would be relevant for an assessment: in some cases, a single-substance based assessment/regulation may be sufficient, while in other cases several components might need to be addressed.

\footnotetext{
${ }^{1}$ Persistent, Bioaccumulative and Toxic, very Persistent and very Bioaccumulative, Persistent, Mobile and Toxic, very Persistent and very Mobile, Endocrine Disrupter.
} 


\section{Assessment of combined effects}

In cases where a real mixture is available on hand and testable, a whole mixture approach is one way to assess the overall toxicity. However, this is only applicable for certain formulations (for example, during classification and labelling), or samples from emissions or environmental compartments and only valid for this specific situation.

Component-based approaches, i.e. CA and IA are well established to predict mixture toxicities based on available ecotoxicity data, usually effect concentrations. In particular, CA is widely accepted as feasible and sound default approach in the environmental context [43]: it relies on effect concentrations for the individual components (i.e. EC10 or EC50, NOECs or LOECs), what makes it less demanding than IA. CA also works considerably well in case of different modes of actions, where IA typically is used. However, CA often predicts higher toxicities than IA and therefore is known to be more conservative, i.e. precautious. For rare cases, specific analyses for the consideration of potential synergisms might be meaningful. In the REACH context, one would most often have to deal with the reported PNEC value(s) based on differing underlying data (QSAR estimates, ecotoxicological standard data for few species from different trophic levels). These would be used when calculating mixture risks. Here, using CA may be challenging as PNECs may rely on data for species from different trophic levels.

\section{Assessment of combined exposures}

The concentrations of the individual components of a "whole mixture" may be analysed by means of chemical analyses to gain information on the composition.

Theoretically, similar to other substance-oriented regulations, predicted environmental exposure concentrations for intentional mixtures could be determined by summation of the calculated PECs by the registrants and/ or DU for the respective environmental compartments.

More sophisticated approaches such as co-exposure modelling are valuable to characterize exposures of unintentional mixtures in the environment on a European scale, but rely on information on uses, production volumes, and fate properties [39]. Knowledge on measured co-exposures of major components in sewage treatment plants [23] and surface waters may get better available via the European Data Platform IPCHEM [70]. Besides identifying relevant substances for a mixture assessment, monitoring and/or modelling data can be used to better define background concentrations for the PEC estimate that also might take aggregated and combined exposures to further substances into account.
Risk characterizations to estimate a safe use conditions for the environment

Under other substance-oriented frameworks, a risk characterization of intentional mixtures is in principle done via component-based approaches by a summation of $\mathrm{PEC} / \mathrm{PNEC}$ ratios for the relevant ingredients by applicants and authorities during product authorization in order to estimate a safe use. This is unfeasible for REACH due to the aforementioned limited availability of information on the mixture compositions (see also Fig. 2).

For unintentional mixtures present in the environment, potential risks can be evaluated by means of modelling approaches or comparisons of predicted or measured exposure information together with effect data or threshold values (PNECs, EQS) for single substances. This relies on the availability of data on substance properties, fate, use amounts and exposures. For example, van Gils et al. [39] used production volumes, fate properties and publicly available ecotoxicity data (e.g. PNEC) to predict possible joint risks of chemicals on a European scale. Malaj et al. [46] predicted risks of joint occurrences of chemicals in European surface waters based on measured concentrations from monitoring programmes and environmental quality standards.

\section{Approaches for a generic assessment: mixture allocation factor}

Specific assessments are very laborious, need a sound data basis and conflict with different responsibilities and knowledge of the actors within REACH. Hence, generic assessment approaches may be a pragmatic default option that could be established during the environmental risk assessment and/or management of chemicals, in particular to take account for unintentional co-occurrences in the environment. The safety factors applied within REACH for PNEC derivation are only covering uncertainties due to biotic interactions and the complexity of ecosystems but are not covering combined effects or co-occurrences of substances [48].

The use of a so-called mixture assessment/allocation factor (MAF), has been proposed and is currently discussed at EU level $[2,3,8,10,21,22]$ to address risks of unintentional mixtures during the single substances "chemicals safety assessment". This would go beyond the single substance paradigm of the current legislations aiming at a reduction of the toxic pressure due to joint occurrences, effects and risks. The current proposals envisage a reduction of the current size of the RCR $[2,8,10,21]$. Hence, the RCR would be interpreted as contribution of a substance to the overall risk of unintentional multiple substances in the environment instead of the single 
substances' risks [2]. The appropriate magnitude of such a measure should be determined based on scientific evidence that is available from monitoring, modelling and/ or experimental studies [23, 56]. Recently, [3] provided a possible approach to derive an appropriate order of magnitude of a MAF. Still, central questions and challenges remain with respect to an implementation (Table 3).

\section{Options within the different REACH processes}

In the following paragraphs, the different options to adress intentional and unintentional mixtures within the different REACH processes are discussed. This is illustrated in Fig. 3.

\section{Chemical safety assessment to ensure safe use for intentional mixtures}

Following the setup of REACH, a consideration of intentional mixtures during the CSA of the registrant to ensure safe uses would be appropriate. But in order to do so, the registrant would require information on the further use of his substance in intentional mixtures and detailed sector-specific information on uses and compositions of formulated mixtures as well as regularly updated use amounts. In theory, this could be communicated upstream via reporting templates, such as the templates for the "safe use of mixtures information" (SUMI), developed by CEFIC [14]. However, this is challenging in light of the presumably enormous number of intentional mixtures and confidential information on compositions. Backhaus et al. [2] proposed to use the product categories (PC) as specified in ECHA Guidance Document R.12 on the use descriptor system to generate exposure scenarios for groups of chemicals. However, a specification for somehow standardized mixtures would either be very generic or lead to a tremendous number of possible PCs. A compilation of typical compositions and/or the self-classifications of intentional mixtures in databases accessible for authorities and registrants would, however, be valuable in order to gain knowledge on the substances sources during the life cycle and possible later co-occurrences of substances. The improved use of the SPIN database as product register was recently proposed by Rudén et al. [56].

\section{Downstream assessment of safe use for intentional mixtures}

As the downstream formulators know compositions and are obliged to classify hazards and ensure the safe use of their own intentional mixtures, they seem to be the appropriate actors to address the potential combined effects, exposures and risks of substances and mixtures they use. However, in particular small and medium-sized enterprises (SMEs) are extremely challenged by the limited information in the (e)SDS together with limited capacities to generate data and conduct own assessments.

Recently, the European Chemical Industry Council CEFIC [14] proposed a "lead component identification methodology" (LCID) together with reporting templates for the "safe use of mixtures information" (SUMI) for downstream-user to improve the communication along the supply chain for hazardous substances in intentional mixtures.

LCID is a working tool aiming at an improved assessment of the safe use conditions of classified substances in intentional mixtures [14], but it aims not per se at the assessment of joint toxicities, exposures or risks. The gaps of the methodology with respect to the environment were analysed by Reihlen et al. [54], as well as Galert and Hassold [38]. Although based on Concentration Addition, a prioritization approach (MCR) is used to determine a lead component for which the safe use is to be ensured by adapting the initial $\mathrm{M}_{\text {safe }}$ and/or RMM provided by the registrants. Here, only substances that are classified with respect to the protection goal (for the environment: hazardous to the aquatic environment) and those for which information is available in the safety data sheets provided by the registrant (using the most sensitive PNEC leading to classification) are considered. Also, SVHCs are currently not included as these are separately assessed. Sub-lead substances are only considered when it makes up at least $10 \%$ of the lead substance. The method has its origin in human health assessment, where derived risk mitigation measures aim at the appropriate protective equipment for workers (e.g. gloves) and it is assumed, that "if the risk of most hazardous substance(s) is/are controlled, then risks for other substance in the mixture are controlled". However, this is different for the environmental assessment, because here, specific safe use amounts and environmental release concentrations are to be derived and also further substances and smaller amounts may be released to the environment and contribute to effects. With LCID, further potentially relevant components in a mixture, in particular those that are not yet classified under CLP, or certain substances of concern seem not to be considered sufficiently. One attempt could be the introduction of "Mixture Assessment Triggering Substances" (MATS), as proposed by Bunke et al. [10] which could be defined by authorities on the basis of certain hazardous properties, high concentrations in the environment or potential risks and would trigger the need for an assessment of mixtures which contain such substances. 


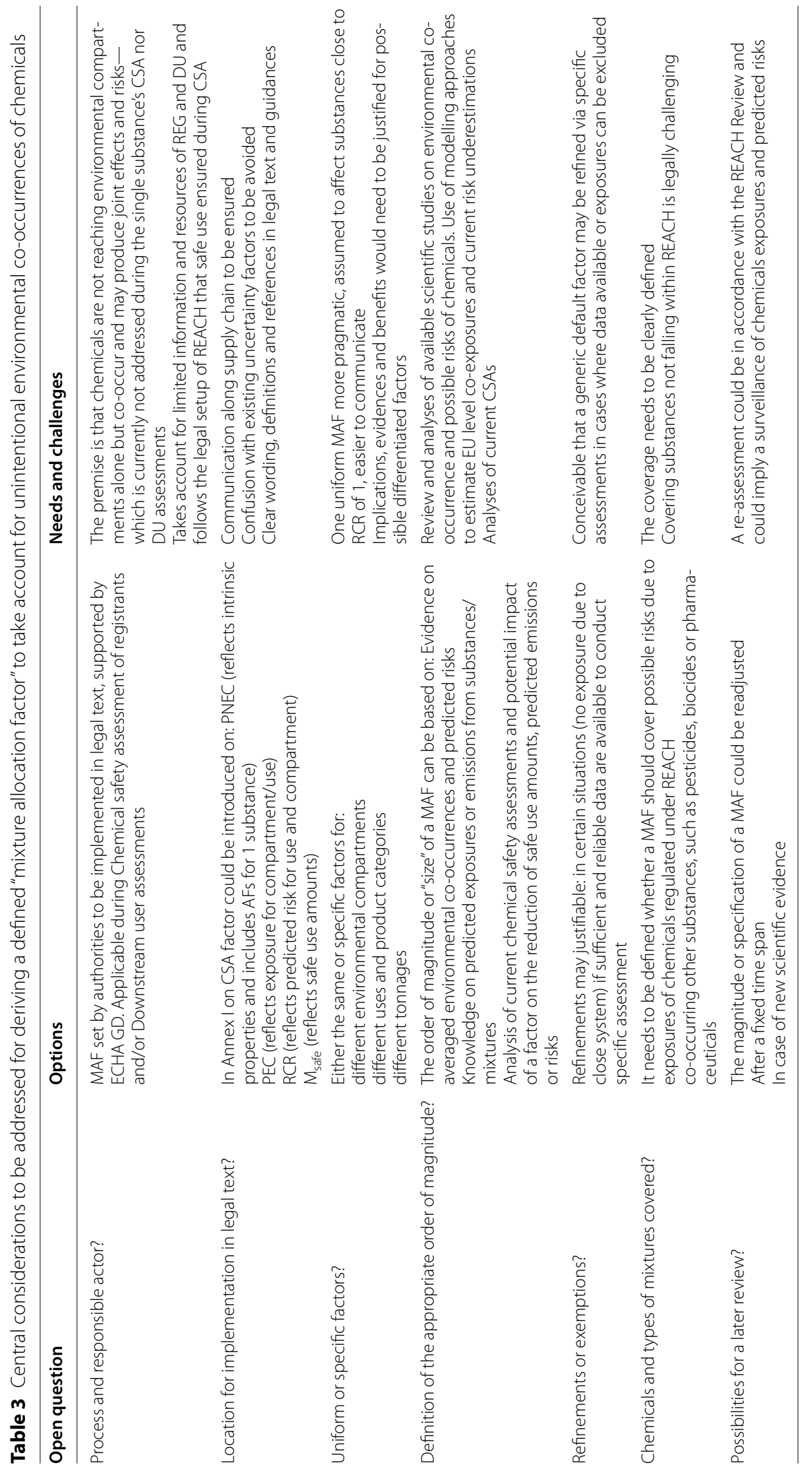




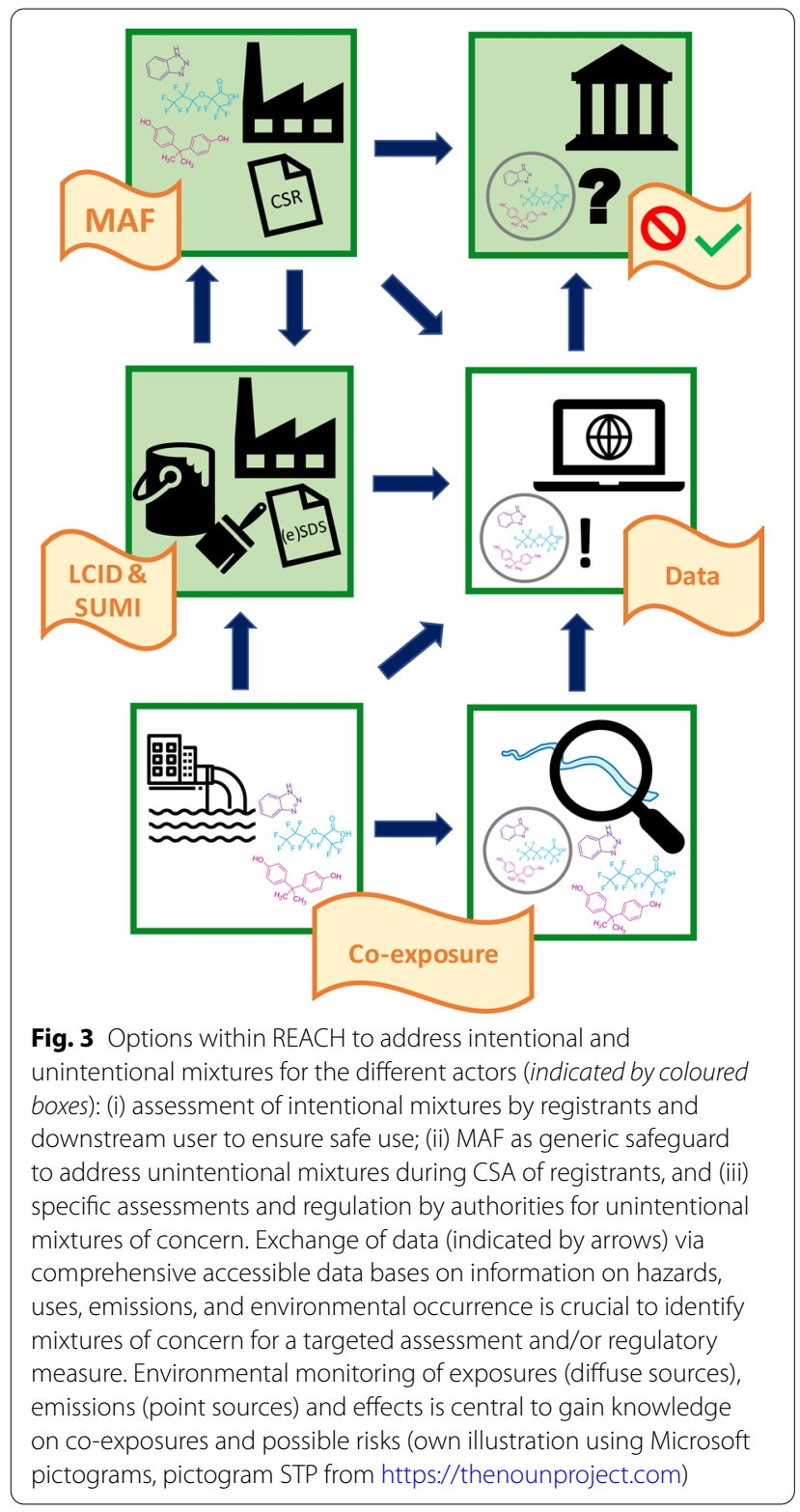

\section{Addressing unintentional co-occurrences during chemical} safety assessments

Due to the previously mentioned missing legal obligations, but most of all limited resources, and the limited information availability on co-exposures, specific assessments of unintentional mixtures seem unfeasible for registrants and downstream-user. Hence, a generic approach or "mixture allocation factor" as proposed by $[2,8,10$, 56 ] could be a feasible option to address unintentional mixtures during the CSA. Legally, a MAF could be implemented in REACH Annex I describing the obligations for risk characterization during the CSA as proposed by $[8,21]$. An allocation factor could be included during
PNEC, PEC, RCR or $\mathrm{M}_{\text {safe }}$ estimations (as these are communicated downstream) for each use of a substance to safeguard for co-exposures. It is to be assumed, that in particular those substances with RCRs close to 1 for the respective uses and compartments would be affected by such as factor. Defining the magnitude of such a factor, still requires analyses of, e.g. environmental monitoring data on concentrations, co-occurrences and effects. Also, the benefits and impacts on chemical safety assessments and resulting environmental emissions, and whether the most relevant substances would be addressed, have to be carefully analysed (see also Table 3 ).

\section{Addressing emissions from production or sewage treatment plants}

While REACH provides the prospective assessment of chemicals and sets the limits for a "safe" use, production volumes and potential emissions, further associated regulations are in close interaction. In order to avoid and minimize industrial emissions, production plant and industrial wastewater treatment plant operators are obliged to follow the Industrial Emissions Directive (IED, Directive 2010/75/EU [60]) and its Best available technique Reference Documents (BREFs), which set provisions for surveillance. They are also obliged to achieve a defined clearance level according to Directive 91/271/ EEC on urban waste water treatment. Emission thresholds only exist for very few chemicals or sum parameters for groups (e.g. for benzoles). Therefore, proposals were made by the EU-project "Hazardous Chemicals in IED BREFs" (HAZBREF) [69], to improve the data basis for single chemicals. A register for substances emitted by industrial sites was proposed [58]. The German Pollutant Release and Transfer Register (PRTR) [72] and its European counterpart (E-PRTR) [68] could be used and extended as data source for emissions. This could support documentation and assessments of groups of substances and co-occurrences closer to the emissions via point sources.

A whole effluent assessment of multiple co-occurring substances is not done on a regular basis neither in industrial nor in municipal treatment plants. Although the problem of so-called micropollutants in sewage treatment plants has been well recognized, the focus is still on single substances [1]. A fourth sewage treatment stage is discussed as a generic solution to reduce the toxic pressure [35]. However, many substances enter environmental compartments via various other diffuse pathways and are not captured. Here, the environmental monitoring for selected priority substances under the Water Framework Directive (2000/60/EC) and Annex I to Directive 2013/39/EU on environmental quality standards (EQSs) could be improved. The existing specifications to 
calculate an EQSmix certainly help to address unintentional mixtures [17].

\section{Specific assessments by authorities to clarify possible mixture risks}

Following the existing instruments of $\mathrm{REACH}$, specific assessments of unintentional co-occurrence in the environment can be conducted by authorities (ECHA and member states) in certain cases, i.e. when additional mixture risks or hazards are indicated. This could be done as part of the screening process in preparation of regulatory assessments, risk management option analyses (RMOA), or during the formal substance evaluation (SEV) to clarify justified concerns. For this purpose, groups of substances, co-occurrences, or mixture scenarios would need to be defined together with the suspected risks to justify inclusion on the CoRAP and a formal SEV. During substance evaluations, the respective CSRs and all other available information could be analysed for defined groups of substances. Subsequently, further data on uses, combined releases or exposures could be requested to be able to conclude on possible mixture risks [10].

Currently, ECHA increases efforts on grouping approaches for a common assessment in order to prioritize substances with similar properties (e.g. bisphenols or PFAS) for further regulatory actions and to avoid regrettable substitutions. Rudén et al. [56] proposed to strengthen group-wise assessments. Grouping could be used to define a sort of cumulative assessment groups of substances with similar structures or hazard profiles that might pose joint risks. Also, groups or scenarios of dissimilar substances could be defined that enter the environment via similar sources and/or are typically cooccurring in the environment.

In order to decide which unintentional mixture or co-occurrence is relevant for further assessments and possible regulation, the definition of a typical "priority" mixture and its key components is needed. Bunke et al. [10] proposed to define priority mixtures that have a high likelihood for combined risks on the basis of their composition, critical uses or relevant co-exposures exceeding predicted risks. For this purpose, risk modelling approaches as provided for example by Gils et al. [39] seem to be promising providing knowledge on relevant exposures on a European or regional scale and evidences for possible mixture risks. As basis, knowledge on production volumes, uses, substance properties would be needed. An improved environmental monitoring that considers environmental co-occurrences of substances and ways to deal with high temporal and spatial variability is also crucial.

\section{Targeted regulatory measures to address drivers} of unintentional mixture risks

In cases, where potential risks of co-occurring substances can be demonstrated, regulatory measures might be taken in order to reduce substance concentrations and impact on ecosystems using the instruments established within REACH.

Restriction seem to be the most suitable approach to regulate mixtures of "definable" composition as some experiences were gained. A restriction was already achieved for a group of 4 phthalates in 2017 (Annex XVII, entry 51) after a proposal of DK proving their joint toxicity, exposure and risks for human health, although the justification and proof of co-exposure was challenging. This way a threshold concentration for the sum of a group of substances is set, as e.g. also for the existing restriction for polyaromatic hydrocarbons $(\mathrm{PAH})$ in consumer products. A recent example with respect to environmental risks is the envisaged restriction proposal for PFAS [33]. Currently, the focus for these defined coexposure scenarios is on well-known and partly already regulated similar substances. This is in line with the proposal of [56] to "flag" suspected substances with similar properties as already restricted ones in order to regulate further relevant substances. However, restrictions could also be possible for groups of dissimilar substances with similar use and exposure profiles.

For those substances identified as SVHCs according to article 57 (PBT or ED), the identification process might be sped up by flagging substances as "suspected" belonging to a structural similar group as proposed by Rudén et al. [56]. However, groups can easily contain hundreds of substances with different hazard profiles as for example currently seen for the group of bisphenols. Although assessments may be conducted group-wise, a possible identification as SVHC would be based on the single substances' properties. However, evidences for co-exposures have already been used as an argument during the assessment of the "equivalent level of concern" (ELOC) during SVHC identification according to article $57 \mathrm{f}$ (for example for the PFAS "HFPO-DA" [33]. Subsequently it would be an option to consider evidence on co-exposures of similar substances during the prioritization process for inclusion of a substance into Annex XIV and the following authorization procedure. In addition to the obligation to clarify common uses in the application for authorization, the consideration of co-exposures in the environment could be assessed during decision-making for granting or denying an authorization. 


\section{Conclusions and further needs}

Clear mandates and guidance to address combined effects and exposures

Currently, $\mathrm{REACH}$ is a single substance-oriented framework and does not explicitly consider the possible joint additive effects and exposures of chemicals neither with respect to intended nor unintentional mixtures. Under the premise that chemicals are neither used alone nor are entering environmental compartments alone but cooccur and may produce joint effects and risks, clear mandates and legal obligations would be needed in the legal text as already proposed by Bunke et al. [10] and Rudén et al. [56]. Experiences under PPPR and BPR show that such a mandate could facilitate and trigger the further development of tools and ensure an enforcement of a mixture assessments. The development of detailed guidance and tools for the different actors under $\mathrm{REACH}$, in particular DUs, is essential and would need to be integrated in the respective ECHA guidance documents as proposed by Bunke et al. [10] in more detail.

\section{Sound data basis on co-occurrences via accessible common databases}

As has become clear, extensive knowledge gaps have to be closed and data made available to the different actors along the supply chain (upstream and downstream) to enable single substance and mixture assessments for compliant safe use conditions. This concerns data on substance properties, uses, fate and behaviour, and amounts produced as well as environmental monitoring data. To reach this, the ECHA dissemination website [62], which currently compiles data on the publicly available substance properties, could be extended with available data on exposures, uses and typical formulations provided that these are made available by companies at least on a generic level. Here, it would be crucial that issues with confidential business information can be addressed in an appropriate way.

With respect to substance concentrations in environmental compartments more monitoring data are needed, as for example provided in a limited way via the retrospective media-oriented frameworks such as the WFD. The EU platform IPCHEM [70] is becoming central and besides data on single substances already includes data on co-occurrences. In order to better link exposures to effects on organisms in the environment and establish possible causal relationships, effect-based tools gain more and more consideration [7]. Furthermore, modelling approaches may allow for the identification of environmental co-occurrences and possible risks on regional or EU level on the basis of available data and again feed into a common data basis.
Safe use for intentional mixtures

From a prospective point of view, mixtures should be tackled at the source and emissions reduced before substances enter environmental compartments. Following the aims of REACH to ensure a high level of protection and the burden of proof for a safe use of chemicals during their life cycle, also the safe use of intentional mixtures should be ensured during the CSA by registrants and DUs. The proposed LCID methodology and SUMI reporting templates seem to be valuable communication tools for mixtures, but still need substantial improvements. They should be further followed up with respect to their acceptance and practicability to reach a transparent communication of information between the actors. Furthermore, case studies and analyses are warranted checking their soundness, benefits and impacts to ensure safe use amounts of formulated mixtures. Possible emissions, joint effects and possible risks for the environment arising from an intentional mixture need to be taken in account.

\section{Generic mixture assessment factor to address unintentional co-exposures in CSA}

Following the principal setup of REACH, also the unintentional co-occurrence of multiple chemicals in the environment should be considered during the CSA. This would account for the fact that single substances are not released to an unpolluted environment. Specific mixture assessments go beyond the information availability on mixture compositions, resources and the direct responsibilities of registrants or DU. Additionally, such assessments are challenging due to the high spatial-temporal variability of substances in the environment and the difficulty to trace substances back to their source and allocate responsible companies. A generic approach such as a mixture allocation factor (MAF) may be a feasible solution, although efforts are needed to define an appropriate size and assess its benefits, possible impacts and challenges for a possible implementation. Further considerations are needed whether such a factor would only address chemicals regulated under $\mathrm{REACH}$ and how to deal with co-occurrences with other substances such as pesticides or pharmaceuticals, which is outside the scope of REACH.

\section{Specific assessment and targeted regulation of identified drivers of possible mixture risks}

In certain cases when indications for remaining risks are available and drivers are identified, targeted mixture risk assessments could be done by the regulatory authorities using the established REACH instruments as for example substance evaluations and subsequent restrictions if 
regulatory measures are needed. This implies comprehensive data on substance's co-occurrences and properties and the definition and prioritization of relevant components of an unintentional environmental mixture. Assessments can be done on the basis of the current legal obligations. Some experiences are already available and current efforts with respect to grouping and prioritization approaches would need to be stepped up.

\section{Increase cross-talk between frameworks}

A (formalized) cross-talk between substance and media-oriented frameworks would be needed to link retrospective data on environmental occurrences and effects better to the prospective risk management measures for substances and mixtures of concern. Overall, a close interaction of the different substance and media-oriented regulations is needed and should be considered when analysing options to assess and regulate mixtures of concern.

\section{Abbreviations}

$\mathrm{BP}(\mathrm{R})$ : Biocidal products (regulation); BREFS: Best available technique Reference Documents in the context of the Industrial Emissions Directive; CA: Concentration Addition; $\mathrm{CCH}$ : Compliance check of dossiers, conducted by ECHA for certain selected registration dossiers; CLP: Classification, Labelling and Packaging of substances and mixtures (EC 1272/2008) regulation; CoRAP: ECHA's Community Rolling Action Plan; CSA: Chemical safety assessment; CSR: Chemical safety report; DU: Downstream user; EC: European Commission; ECHA: European Chemicals Agency; EC10: Concentration, where 10\% effect is observed; ED: Endocrine disrupters; ELOC: Equivalent level of concern during SVHC identification under REACH; EQS: Environmental quality standard in the context of the water framework directive; eSDS: Extended safety data sheet; HCBM: Hydrocarbon block methodology; IA: Independent Action; IED: Industrial Emissions Directive; LCID: Lead component identification methodology; LOEC: Statistically determined and tested lowest observed effect concentration; MAF: Mixture assessment/allocation factor; MATS: Mixture Assessment Triggering Substances; MCR: Maximum cumulative ratio; $M_{\text {safe }}$ : Maximum safe use amount (kg/day or kg/year); MSC: Multi constituent substances; NOEC: No observed effect concentration, lowest tested concentration with no significant effect; OCs: Operational conditions; P(H)S: Priority (hazardous) substances in the context of the water framework directive; PBT/VPvB: Substances, which are persistent, bioaccumulative and toxic/very persistent and very bioaccumulative according to REACH Annex XVIII; PC: Product category; PEC: Predicted Environmental Concentration; PMT/VPVM: Substances, which are persistent, mobile and toxic / very persistent and very mobile; PNEC: Predicted No Effect Concentration; PPP(R): Plant protection products (regulation); PRTR: German Pollutant Release and Transfer Register; QSAR: Quantitative structure activity relationships; RCR: Risk characterization ratio; REACH: Regulation EC 1907/2006 of the European Parliament and of the Council of 18 December 2006 concerning the Registration, Evaluation, Authorisation and Restriction of Chemicals; RMM: Risk mitigation measures; SDS: Safety data sheet; SEV: Substance evaluation, conducted by member state competent authorities as formal process under REACH; SME: Small and medium-sized enterprises; spERCs: Specific environmental release categories; SUMI: Reporting template for the safe use of mixtures information; SVHC: Substances of very high concern according to REACH Article 57; TPE: Testing proposal evaluation, conducted by ECHA if tests are proposed by registrant; UVCB: Substances of unknown or variable composition and biological materials.
\end{abstract}

\section{Acknowledgements}

The authors thank Eva-Maria Burkhardt, Daniel Sättler, Nannett Aust, and Wiebke Drost for constructive discussions and review of the manuscript.

\section{Disclaimer}

The views expressed are those of the authors and do not necessarily represent the official position of their organization.

\section{Authors' contributions}

All authors contributed with their expertise to the manuscript. EH mainly contributed with conceptualization of figures and text and writing the final version of the manuscript. WG in particular contributed with details on exposure assessments and supply chain requirements and designed the figures. JS in particular reviewed, adapted and improved the entire manuscript and finetuned all the figures. All authors read and approved the final manuscript.

\section{Funding}

The cited research projects conducted on behalf of UBA were financed in the context of the national environmental research program of the German Ministry for Environment (Project Numbers: FKZ 371163 429, FKZ 371063403, FKZ 36001 058). We received no further financial support from external sources. Open Access funding enabled and organized by Projekt DEAL.

\section{Availability of data and materials}

Data sharing is not applicable to this article as no datasets were generated or analysed during the current study.

\section{Declarations}

Ethics approval and consent to participate

Not applicable.

\section{Consent for publication}

Not applicable.

\section{Competing interests}

The authors declare that they have no competing interests.

Received: 9 July 2021 Accepted: 19 October 2021

Published: 27 November 2021

\section{References}

1. Ahting M, Brauer F, Duffek A, Ebert I, Eckhardt A, Hassold E, Helmecke M, Kirst I, Krause B, Lepom P et al. (2018) Recommendations for reducing micropollutants in waters-background paper German environment agency. ISSN 2363-829x

2. Backhaus T, Blanck H, Faust M (2010) Hazard and risk assessment of chemical mixtures under REACH — state of the art, gaps and options for improvement. PM 3/10. Swedish chemicals agency-KEMl (http://www. Kemi.Se)

3. Backhaus 2021. Improving the regulatory assessment of combination effects: steps towards implementing the mixture assessment factor (MAF) in chemical regulation; report PM 8/21, Swedish Chemicals Agency KEMl; Article number: 511 421. https://www.kemi.se/publikationer/pm/2021/ pm-8-21-improving-the-regulatory-assessment-of-combination-effec ts-steps-towards-implementing-the-mixture-assessment-factor-maf-inchemical-regulation

4. Bopp S, Berggren E, Kienzler A, Linden Svd, Worth A (2015) Scientific methodologies for the assessment of combined effects of chemicals-a survey and literature review. J Tech Rep. Eur 27471 en. European Union

5. Bopp SK, Kienzler A, Linden Svd, Lamon L, Paini A, Parissis N, Richarz A-N, Triebe J, Worth A (2016) Review of case studies on the human and environmental risk assessment of chemical mixtures. J Tech Rep Eur 27968 en. https://doi.org/10.2788/272583

6. Bopp SK, Kienzler A, Richarz AN, van der Linden SC, Paini A, Parissis N, Worth AP (2019) Regulatory assessment and risk management of chemical mixtures: challenges and ways forward. Crit Rev Toxicol 49(2):174-189

7. Brack W, Altenburger R, Schüürmann G, Krauss M, López Herráez D, van Gils J, Slobodnik J, Munthe J, Gawlik BM, van Wezel A et al (2015) The solutions project: challenges and responses for present and future emerging pollutants in land and water resources management. Sci Total Environ 503-504:22-31 
8. Broekhuizen FAv, Posthuma L, Traas TP (2016) Addressing combined effects of chemicals in environmental safety assessment under reach-a thought starter. Rivm letter report 2016-0162. National institute for public health and the environment

9. Bunke D, Groß R, Gartiser S (2011) Basic principles for the development of a concept for environmental exposure assessments of single substances released from multiple uses under REACH. UBA Texte. No. 001529/E

10. Bunke D, Groß R, Kalberlah F, Reihlen A, Reineke N, Oltmanns J, Schwarz $M$ (2014) Mixtures in the environment-development of assessment strategies for the regulation of chemicals under REACH. No. 371163429

11. Busch W, Schmidt S, Kühne R, Schulze T, Krauss M, Altenburger R (2016) Micropollutants in European rivers: a mode of action survey to support the development of effect-based tools for water monitoring. Environ Toxicol Chem 35(8):1887-1899

12. Carvalho RN, Arukwe A, Ait-Aissa S, Bado-Nilles A, Balzamo S, Baun A, Belkin S, Blaha L, Brion F, Conti D et al (2014) Mixtures of chemical pollutants at European legislation safety concentrations: how safe are they? Toxicol Sci 141(1):218-233

13. Cedergreen N (2014) Quantifying synergy: a systematic review of mixture toxicity studies within environmental toxicology. PLoS ONE 9(5):e96580

14. CEFIC (2016) Reach practical guide on safe use information for mixtures under reach - the lead component identification (LCID) methodology. Final version 6.1-25 February 2016. Created by the European chemical industry council (CEFIC) and VCI (Verband der chemischen Industrie e.V.) as a contribution to the CSR/ES roadmap (action 4.4a; http://echa.Europa. Eu/regulations/reach/registration/informationrequirements/chemicalsafety-report/csr-es-roadmap)

15. Commission (2006) Regulation (ec) no 1907/2006 of the European parliament and of the council of 18 December 2006 concerning the registration, evaluation, authorisation and restriction of chemicals (reach), establishing a European chemicals agency, amending directive 1999/45/ ec and repealing council regulation (eec) no 793/93 and commission regulation (ec) no 1488/94 as well as council directive 76/769/eec and commission directives 91/155/eec, 93/67/eec, 93/105/ec and 2000/21/ ec.

16. Commission (2008) Regulation (ec) no 1272/2008 of the European parliament and of the council on classification, labelling and packaging of substances and mixtures, amending and repealing directives 67/548/eec and 1999/45/ec, and amending regulation (ec) no 1907/2006

17. Commission (2012a) Common implementation strategy for the water framework directive (2000/60/ec) — guidance document no. 28, technical guidance on the preparation of an inventory of emissions, discharges and losses of priority and priority hazardous substances. European commission

18. Commission (2012b) Communication from the commission to the council, 'the combination effects of chemicals, chemical mixtures' com(2012) 252 final. European commission

19. Commission (2012c) Toxicity and assessment of chemical mixtures. Scientific committee on health and environmental risks (scher). Scientific committee on emerging and newly identified health risks (scenihr). Scientific committee on consumer safety (sccs). European commission. Nd-03-13-259-en-n

20. Commission (2019) Communication from the commission to the European parliament, the European council, the council, the European economic and social committee and the committee of the regions. 'The European green deal', com(2019) 640 final. European commission

21. Commission (2020a) Discussion paper for caracal provided by kemi and the Netherlands. Towards a pragmatic procedure to regulate the risks of exposure to unintended combinations of chemicals in the eu. 34th meeting of competent authorities for reach and clp (caracal) open session, 31 march-1 April 2020. Doc. Ca/ms/34/2020, European commission 25 mars 2020

22. Commission (2020b) Progress report on the assessment and management of combined exposures to multiple chemicals (chemical mixtures) and associated risks (staff working document accompanying the communication of the commission on the "chemicals strategy for sustainability towards a toxic-free environment"). European commission. Swd(2020) 250 final

23. Coors A, Vollmar P, Sacher F, Polleichtner C, Hassold E, Gildemeister D, Kühnen U (2018) Prospective environmental risk assessment of mixtures in wastewater treatment plant effluents-theoretical considerations and experimental verification. Water Res 140:56-66

24. Council (2009) Council conclusions on combination effects of chemicals. Environment council. 2988th environment council meeting Brussels, 22 December 2009

25. Council (2019) Council conclusions: Towards a sustainable chemicals policy strategy of the union, 10713/19, 26 June 2019. Environment council

26. ECHA (2008) Guidance on information requirements and chemical safety assessment-chapter r.6-qsars and grouping of chemicals. European chemicals agency (echa)

27. ECHA (2014) Guidance for downstream user. version 2.1

28. ECHA (2015) Guidance on the compilation of safety data sheets

29. ECHA (2016) Guidance on information requirements and chemical safety assessment, chapter r.16: Environmental exposure assessment. European chemicals agency. ECHA-16-G-03-EN

30. ECHA (2017a) Guidance on the application of the clp criteria guidance to regulation (ec) no 1272/2008 on classification, labelling and packaging (clp) of substances and mixtures. European chemicals agency. Echa-17-g-21-en

31. ECHA (2017b) Guidance on the biocidal products regulation volume iv environment-assessment and evaluation part $\mathrm{b}+\mathrm{c}$. European chemicals agency. ECHA-17-G-23-EN

32. ECHA (2017c) Read-across assessment framework (raaf) — considerations on multiconstituent substances and uvcbs (echa-17-r-04-en). European chemicals agency (echa)

33. ECHA (2019) SVHC support document for identification of 2,3,3,3-Tetrafluoro-2-(heptafluoropropoxy)Propionic acid, its salts and its acyl halides (covering any of their individual isomers and combinations thereof) as Substances of Very High Concern because of their hazardous properties which cause probable serious effects to human health and the environment which give rise to an equivalent level of concern to those of CMR and PBT/vPvB substances (Article 57F); adopted on 26 June 2019 (p. 110). https://echa.europa.eu/substance-information/-/substanceinfo/100.308. 021.

34. EFSA (2013) Guidance on tiered risk assessment for plant protection products for aquatic organisms in edge-of-field surface waters. European food safety authority (efsa) EFSA J 11(7)

35. Eggen RIL, Hollender J, Joss A, Schärer M, Stamm C (2014) Reducing the discharge of micropollutants in the aquatic environment: the benefits of upgrading wastewater treatment plants. Environ Sci Technol 48(14):7683-7689

36. EMEA (2006) Guideline on pharmaceutical fixed combination products_emea/cvmp/83804/2005 European medicines agency veterinary medicines and inspections_-cvmp committee for medicinal products for veterinary use. European medicines agency (emea)

37. Frische T, Matezki S, Wogram J (2014) Environmental risk assessment of pesticide mixtures under regulation 1107/2009/ec: a regulatory review by the German federal environment agency (uba). J Verbr Lebensm 9(4):377-389

38. Galert W, Hassold E (2021) Environmental risk assessment of technical mixtures under the European registration, evaluation, authorisation and restriction of chemicals-a regulatory perspective. Integr Environ Assess Manag 17(3):498-506

39. van Gils J, Posthuma L, Cousins IT, Lindin C, Zwart Dd, Bunke D, Kutsarova S, Müller C, Munthe J, Slobodnik J et al. (2019) The European collaborative project solutions developed models to provide diagnostic and prognostic capacity and fill data gaps for chemicals of emerging concern. Environ Sci Europe 31

40. Kienzler A, Berggren E, Bessems J, Bopp S, van der Linden S, Worth A (2014) Assessment of mixtures-review of regulatory requirements and guidance. Joint Research Centre, Science and Policy Reports Luxembourg, European Commission

41. Kienzler A, Bopp S, van der Linden S, Berggren E, Worth A (2016) Regulatory assessment of chemical mixtures: requirements, current approaches and future perspectives'. Regul Toxicol Pharmacol 80:321-334

42. King DJ, Lyne RL, Girling A, Peterson DR, Stephenson R, Short D (1996) Environmental risk assessment of petroleum substances: the hydrocarbon block method. Concawe. Report no 96/52

43. Kortenkamp A, Backhaus T, Faust M (2009) State of the art report on mixture toxicity. No. 070307/2007/485103/ETU/D.1 
44. Kortenkamp A, Faust M (2018) Regulate to reduce chemical mixture risk. Science 361 (6399):224-226

45. Loos R, Gawlik BM, Locoro G, Rimaviciute E, Contini S, Bidoglio G (2009) Eu-wide survey of polar organic persistent pollutants in European river waters. Environ Pollut 157(2):561-568

46. Malaj $E$, von der Ohe PC, Grote M, Kühne R, Mondy CP, Usseglio-Polatera P, Brack W, Schäfer RB (2014) Organic chemicals jeopardize the health of freshwater ecosystems on the continental scale. Proc Natl Acad Sci 111(26):9549-9554

47. Martin O, Scholze M, Ermler S, McPhie J, Kortenkamp A (2019) Systematic review of ten years of research on interactions in chemical mixtures of environmental pollutants-European commission, final report service contract ccr.F.933992.X0

48. Martin OV, Scholze M, Kortenkamp A (2013) Dispelling urban myths about default uncertainty factors in chemical risk assessment-sufficient protection against mixture effects? Environ Health 2013:12

49. Meek M, Boobis A, Crofton K, Heinemeyer G, Van Raaij M, Vickers C (2011) Risk assessment of combined exposure to multiple chemicals: a who/ipcs framework. Regul Toxicol Pharmacol 60:1-14

50. More S, Bampidis V, Benford D, Bennekou S, Bragard C, Halldorsson T, Hernandez-Jerez A, K K, H N, JR S et al. (2019) Guidance on harmonised methodologies for human health, animal health and ecological risk assessment of combined exposure to multiple chemicals. EFSA J 17(3):77

51. OECD (2018) Considerations for assessing the risks of combined exposure to multiple chemicals', series on testing and assessment no. 296, environment, health and safety division, environment directorate

52. Price P, Han X, Junghans M, Kunz P, Watts C, Leverett D (2012) An application of a decision tree for assessing effects from exposures to multiple substances to the assessment of human and ecological effects from combined exposures to chemicals observed in surface waters and waste water effluents. Environ Sci Eur 24(1):34

53. Price PS, Han X (2011) Maximum cumulative ratio (mcr) as a tool for assessing the value of performing a cumulative risk assessment. Int J Environ Res Public Health 8(6):2212

54. Reihlen A, Jepsen D, Wirth O. 2012. Consolidation of information for mixtures under reach — analysis of the dpd+ method; project no. Fkz 371063403 german environment agency (uba). Draft final report part i (analysis report) and executive summary. The report is not published but the executive summary is available at: http://www.Reach-hamburg.De/ fileadmin/user_upload/dokumentationen/materialien/4_5_3_kommu nikation_in_der_lieferkette/120430_mixtures_under_reach_exec_ summary.Pdf.

55. Rotter S, Beronius A, Boobis AR, Hanberg A, van Klaveren J, Luijten M, Machera K, Nikolopoulou D, van der Voet H, Zilliacus J, Solecki R (2019) Overview on legislation and scientific approaches for risk assessment of combined exposure to multiple chemicals: the potential euromix contribution. Crit Rev Toxicol 48(9):796-814

56. Rudén C, Backhaus T, Bergman D, Faust M, Molander L, Slunge D (2019) Future chemical risk management-accounting for combination effects and assessing chemicals in groups. Swedish government inquiries-Swedish government official reports. Sou 2019:45. Stockholm
57. Silva E, Rajapakse N, Kortenkamp A (2002) Something from "nothing"-eight weak estrogenic chemicals combined at concentrations below noecs produce significant mixture effects. Environ Sci Technol 36:1751-1756

58. van Wezel AP, van den Hurk F, Sjerps RMA, Meijers EM, Roex EWM, ter LaakTL (2018) Impact of industrial waste water treatment plants on Dutch surface waters and drinking water sources. Sci Total Environ 640-641:1489-1499

\section{Weblinks}

59. Directive 2000/60/EC of the European Parliament and of the Council of 23 October 2000 establishing a framework for Community action in the field of water policy (https://eur-lex.europa.eu/legal-content/DE/TXT/? uri=CELEX:32000LO060)

60. Directive 2010/75/EU of the European Parliament and of the Council of 24 November 2010 on industrial emissions (integrated pollution prevention and control) (http://data.europa.eu/eli/dir/2010/75/oj)

61. ECHA's Community Rolling Action Plan (CoRAP): https://echa.europa. eu/de/information-on-chemicals/evaluation/community-rolling-actionplan/corap-list-of-substances

62. ECHA's dissemination website on registered substances under REACH: https://echa.europa.eu/information-on-chemicals/registered-substances

63. ECHA's candidate list of Substances of Very High Concern for potential inclusion in Annex XIV: ECHA's endocrine disruptor (ED) assessment list: https://echa.europa.eu/de/ed-assessment

64. ECHA's list on restricted substances under REACH: https://echa.europa. eu/de/substances-restricted-under-reach

65. ECHA's inventory on harmonized classified substances: https://echa. europa.eu/de/information-on-chemicals/annex-vi-to-clp

66. ECHA's inventory on self-notified substances: https://echa.europa.eu/de/ information-on-chemicals/cl-inventory-database

67. ECHA's list on authorised substances: https://echa.europa.eu/authorisat ion-list

68. European Industrial Emissions Portal: https://industry.eea.europa.eu/

69. EU-project "Hazardous Chemicals in IED BREFs" (HAZBREF): https://www. syke.fi/projects/hazbref

70. European Data Platform IPCHEM: https://ipchem.jrc.ec.europa.eu/

71. German database on substances hazardous to water in regulation AWSV/22/2017: https://webrigoletto.uba.de/rigoletto

72. German Pollutant Release and Transfer Register (PRTR): https://www.thru. de/thrude/

\section{Publisher's Note}

Springer Nature remains neutral with regard to jurisdictional claims in published maps and institutional affiliations.

\section{Submit your manuscript to a SpringerOpen ${ }^{\odot}$ journal and benefit from:}

- Convenient online submission

- Rigorous peer review

- Open access: articles freely available online

- High visibility within the field

- Retaining the copyright to your article

Submit your next manuscript at $\boldsymbol{\nabla}$ springeropen.com 